\title{
Peran Media Sosial Dalam Pembelajaran Ips Era Globalisasi Di Mi Muhammadiyah Cabang Purbalingga
}

\author{
${ }^{1}$ Pujiyanti, ${ }^{2}$ Tutuk Ningsih \\ ${ }^{1}$ Mahasiswa Prodi Pendidikan Guru Madrasah Ibtidaiyah Pascasarjana, IAIN Purwokerto \\ ${ }^{2}$ Dosen Prodi Pendidikan Guru Madrasah Ibtidaiyah Pascasarjana, IAIN Purwokerto \\ Email: ${ }^{1}$ ypuji3051@gmail.com, ${ }^{2}$ tutuk@iainpurwokerto.ac.id
}

\begin{abstract}
Abstrak. Dengan adanya kesulitan dalam pembelajaran jarak jauh ( PJJ ) pada Pembelajaran IPS MI Muhammadiya Cabang Purbalingga. Tujuan dari penelitian ini yaitu agar dengan menggunakana media sosial dalam pembelajaran IPS guru mampu menyampaikan materi dengan berbagai macam cara yang efisien dan kreatif sehingga siswa tidak merasa cepat bosan dan materi yang di sampaikan dapat di pahami dan di mengerti oleh siswa. Disini peneliti akan mendeskripsikan Peran Media Sosial Dalam Pembelajaran IPS Era Globalisasi di MI Muhammadiyah Cabang Purbalingga. Penelitian yang di gunakan merupakan penelitian kualitatif lapangan dan study pustaka. Teknik pengumpulan data peneliti menggunakana data gabungan dengan teknik observasi, wawancara, dan dokumentasi. Analisis penelitian dilakukan dengan cara reduksi data, pembahasan dan kesimpulan. Hasil dari penelitian yang dilakukan dapat membuktikan bahwa Peran Media Sosial dalam Pembelajaran IPS sangat penting. Pertama dengan menggunakan media sosial guru dapat melakukan pembelajaran dengan kreatif dan efisien. Kedua dengan menggunakan media sosial siswa lebih mudah dalam memahami materi. Dan yang ketiga dengan menggunakan media sosial perkembangan pendidikan mengalami kemajuan.
\end{abstract}

\section{Kata kunci: Peran media sosial, Pembelajaran IPS, Globalisasi}

\begin{abstract}
Abstrack. With the difficulties in distance learning (PJJ) in the Social Studies Learning at MI Muhammadiya Branch of Purbalingga. The purpose of this research is that by using social media in social studies learning the teacher is able to deliver material in a variety of efficient and creative ways so that students do not feel bored quickly and the material conveyed can be understood and understood by students. Here the researcher will describe the role of social media in social studies learning in the era of globalization at MI Muhammadiyah Purbalingga branch. The research used is a qualitative field research and literature study. The researcher's data collection technique used combined data with observation, interview, and documentation techniques. The research analysis was carried out by means of data reduction, discussion and conclusions. The results of the research conducted can prove that the role of social media in social studies learning is very important. First, by using social media, the teacher can learn creatively and efficiently. Second, by using social media, students are easier to understand the material. And the third, by using social media, the development of education has progressed.
\end{abstract}

Keywords: The role of social media, social studies learning, globalization

\section{PENDAHULUAN}

Mengikuti perkembangan teknologi di era globalisasi saat ini terutama dengan menggunakan media sosial dapat membawa siapapun yang berminat untuk brkontribusi dan berpartisispasi dengan memberi feedback secara terbuka dalam memberi komentar serta membagikan informasi dalam waktu singkat dan tak terbatas (Yuni, 2017). Tidak bisa di pungkiri lagi saat ini perkembangan teknologi sangatlah berperan penting dalam sebuah kelangsungan hidup. Terutama dalam bidang informasi, saat ini semua orang sangatlah membutuhkannya dalam membantu setiap kegiatan. Dengan munculnya internet dan media sosial merupakan wujud dari perkembangan teknologi saat ini.

Dari pernyataan diatas dapat dikatakan bahwa pekembangan ilmu sosial pada abad $\mathrm{XX}$ sagat pesat yang meliputi masyrakat. Hal seperti itulah yang dikatakan masyarakat sedang mengalami globalisasi. Globalisasi merupakan asal dari kata global yang memiliki arti dunia, oleh sebab itu globalisasi dapat diartikam sebagai suatu proses masuknya ruang lingkup dunia. Globalisasi 
merupakan era tanpa batas yang di tandai dengan berubahnya struktur sosial masyarakat bagai mana mestinya. Melihat dari perubahan tersebut dapat disimpulkan bahwa keterkaitan masyarakat antara lemen yang terjadi merupakan akibat dari transkulturasi teknologi dan komunikasi yang begitu pesat. Gerakan yang mendunia yang mempengaruhi pembentukan system dan nilai kehidupan baru merupakan arus globalisasi (Ricky \& Erry, 2020).

Dalam era globalisasi dapat dikatakan bahwa setiap kegiatan atau aktivitas itu tidak bisa terlepas dari duni tekhnologi terutama media sosial. Isu yang berkembang saat ini khususnya dalam bidangn pendidikan yang kerap mengenai DIKMAS ( Pendidikan Masyarakat ) dalam menghadapi era globalisasi. Konsepsi pendidikan yang berwawasan global mengajarkan masyarakat luas untuk memahami perubahan tersebut, sehingga mendorong untuk lebih dapat bersaing di masyarakat luas(Ricky \& Erry, 2020).

Tujuan dari penelitian ini yaitu agar dengan menggunakana media sosial dalam pembelajaran IPS guru mampu menyampaikan materi dengan berbagai macam cara yang efisien dan kreatif sehingga siswa tidak merasa cepat bosan dan materi yang di sampaikan dapat di pahami dan di mengerti oleh siswa.

Dari Uraian diatas dapat ditarik kesimpulan bahwa media sosial berperan penting dalam perkembangan dunia di era globalisasi. Dari hal tersebut peneliti tertarik untuk mengamati bagaimana peran media sosial dalam pembelajaran IPS di era globalisasi MI Muhammadiyah Cabang Purbalingga.

\section{METODE PENELITIAN}

Jenis penelitian yang di lakukan merupakan deskriptif kualitatif dengan menjabarkan hasil penelitian yang telah dilakukan. Metode penelitian yang di gunakan yaitu observasi dimana peneliti mencari tau bagai mana peran media sosial pada pembelajarn ips di era globalisasi yang di laksanakan di MI Muhammadiyah Cabang Purbalingga.

Data primer dan data sekunder yang di gunakan oleh peneliti dalam penelitian ini. Peneliti memperoleh data primer dari hasil wawancara yang dilakukan kepada kepala sekolah, guru maupun murid yang dianggap relevan dalam memberikan informasi. Data sekunder yang diambil oleh peneliti yaitu buku - buku mengenai pembelajaran ips serta dokumrn - dokumen yang relevan. Dalam penelitian ini peneliti meminta dokumen dari guru kelas dan siswa sebagai narasumber untuk memperoleh data.

Teknik pengumpulan data yang di gunakan peniliti adalah wawancara, observasi dan dokumentasi. Dengan penggunaan teknik trigulasi sumber peneliti dapat mengecek hasil wawancara yang di peroleh dari beberapa sumber untuk mengecek keakuratan data yang di peroleh.

Analisis model interaktif merupakan model analisis yang di gunakan dalam peneltian ini. Reduksi data merupakan, sajian data dan penarikan simpulan merupakan komponen analisis yang dilakukan dengan cara interaktif dengan proses pengumpulan data sebagai suatu siklus.

\section{HASIL DAN PEMBAHASAN}

\section{Peran Media Sosial dalam Pelajaran IPS}

Hasil penelitian tetang peran media sosial dalam pembelajaran IPS MI Muhammadiyah Cabang Purbalingga di era globalisasi saat ini dapat di tarik kesimpulan bahwa media sosial saat ini sangatlah penting peranannya dalam mendukung kelangsungan dan kelancaran perputaran perkembangan teknologi yang saat ini sagat berkembang pesat dan banyak kegunaanya. Dari hal tersebut peran media sosial dalam pembelajaran IPS. di era globalisasi MI Muhammadiyah Cabang Purbalingga dapat di jabarkan peranan media sosial dengan menggunakan Whatsshap, Youtube, dan Google Class Room.

Di era globalisasi ini pemerintah menuntut lembaga pendidikan untuk mengikuti perkembangan yang semakin maju di bidang teknologinya. Khususnya di MI 
Muhammadiyah Cabang Purbalingga yang memberlakukan pembelajaran jarak jauh tuntutan seperti itulah yang menjadikan MI Mihammadiyah Cabang Purbalingga Menggunakan Media sosial dalam pembelajaran IPS antara lain :

1. Whatsapp

Dalam pembelajaran IPS di MI Muhammadiyah Cabang Purbalingga guru membuat menggunakan media sosial Whatsshap untuk mempermudah komunikasi dan pembelajaran setiap wali kelas membuat Whatsshap Grup di dalam grup tersebut beranggotakan semua siswa perkelas, Wali kelas dan Guru matapelajaran yang mengampu di dalam kelas tersebut.

Metode yang di gunakan menggunakan Whatsshap dengan cara wali kelas maupun guru mata pelajaran menggunakan media sosial whatsapp, misalanya dalam mata pelajaran IPS pada pembahasan keragaman budaya di kelas V MI Muhammadiyah Cabang Purbalingga guru menyampaikan materi pelajaran tentang keragaman budaya dengan mengirimkan voice note yang didalamnya guru menerangkan keragaman budaya yang ada di indonesia selain materi yang disampaikan guru juga menyampaikan tugas kepada siswa. Selanjutnya guru membagikan voice note tersebut ke Whatsshap Grup dan menugaskan anak supaya mendengarkan isi yang ada di dalam voice note tersebut dengan mendengarkan siswa akan mengetahui isi materi dan tugas yang harus di kerjakan oleh siswa. Untuk tugas yang di berikan siswa di beri waktu 1 hari dari soal tersebut di sampaikan, setelah soal tersebut di selesaikan siswa supaya mengirimkan jawabanya via wapri kepada wali kelas maupun guru mata pelajaran.

2. Yuotube

Untuk media sosial yang di gunakan dalam pembelajaran IPS di Mi Muhammadiyaha Cabang Purbalingga selain Whatsshap ada pula youtube. Dalam pembelajaran. IPS guru membuat vidio pembelajaran IPS dengan menggunakan media sosial youtube didalam vidio pembelajaran terdapat materi tentang keragaman budaya di dalamnya di tampilkan gambar- gambar rumah adat, pakaian adat dan lain sebagainya yang berhubungan dengan keragaman budaya. Tampilan didalam video tersebut di buat semenarik mungkin agar siswa tidak mudah bosan. Setelah video pembelajaran tersebut selesai di aplod di media sosial youtube.

Setelah mengupload video pembelajaran ke youtube guru membagikan link untuk membuka youtube yang berisi vido pelajaran yang telah dibuat yang di dalamnya ada materi yang harus di pelajari oleh siswa.

3. Google Class Room

Google Class Room merupakan media sosial yang di dalam aplikasinya terdapat berbagai macam vitur yang di gunakan. Untuk menyampaikan mater pelajaran IPS selain menggunakan Whatsapp Grup dan Yuotube guru juga menggunakan Google Class Room dalam penyampaian materi. Adapun langkah - langkah bagai mana cara mengerjakan tugas menggunakan Google Class Room yaitu :

a. Buka Google Class Room dengan grup kelas yang sudah di buat

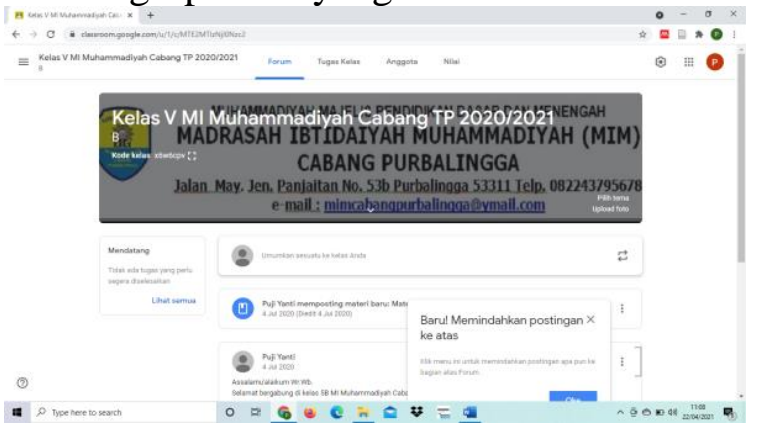

b. Masuk ke tugas kelas buka file yg sudah di bagikan oleh guru mengenai tugas yang harus di kerjakan siswa.

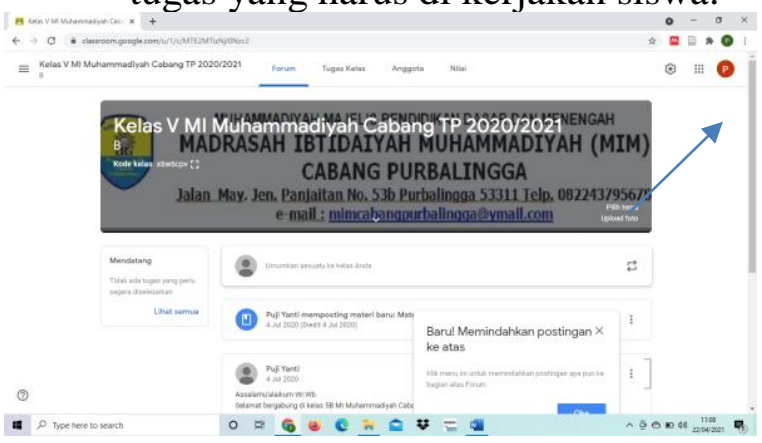

c. Kerjakan tugas tersebut, jika tugas sudah selesai serahkan tugas tersebut melalui Google Class Room 


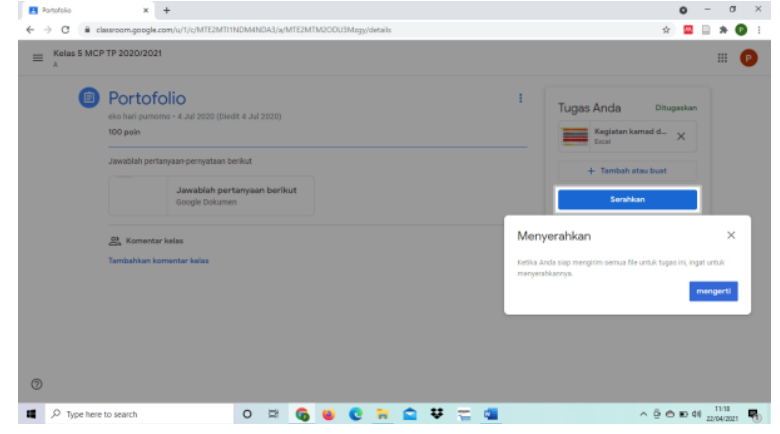

Setelah tugas sudah di serahkan oleh siswa maka guru akan menilai tugas tersebut sebagai bukti bahwa siswa tersebut mengikuti pembelajaran dan mengerjakan tugasnya.

\section{KESIMPULAN}

Dari hasil penelitian yang di lakukan dapat ditarik kesimpulan bahwa peran teknologi di era globalisasi ini sangatlah membantu dalam memajukan suatu kehidupan dalam segala bidang. Dengan menggunakan teknoligi yang semakin berkembang saat ini kita dapat beralih dari zaman tradisional menuju zaman yang moderen. Khususnya dalam bidang pendidikan yang saat ini sedangan mengalami kemunduran. Dengan menggunakan media sosial di bidang pendidikan akan mengubah keadaan dari yang semula menganggap dengan adanya pandemi ini akan mengalami kemunduran tapi malah sebaliknya dengan adanya hal tersebut kita dapat mengggunakan teknologi yang sekarang ini sangat membatu dalam kemajuan dunia pendidikan.

Oleh karena itu peranan media sosial sangatlah berperan penting dalam pembelajaran IPS .

\section{SARAN}

Berdasarkan kesimpulan dan implikasi di atas, maka peneliti mengajukan saran sebagai berikut:

1. Kepada Kepala Madrasah

$$
\text { Selalu merespon terhadap }
$$
perkembangan teori mengenai metode peran teknologi di era globalisasi ini sangatlah membantu dalam memajukan suatu kehidupan dalam segala bidang terutama dalam bidang pendidikan, sehingga guru dapat lebih kreatif dalam melakukan proses pengajaran.

2. Kepada Guru a. Dalam pembelajaran jarak jauh, guru dapat lebih kreatif menggunakan berbagai media sosial sehingga pelajaran lebih menarik.

b. Dalam pembelajaran guru memberikan kesempatan untuk melatih kesiapan dan kemandirian peserta didik dalam belajar sendiri dirumah.

3. Kepada Peserta Didik

Hendaknya peserta didik menjadi lebih giat belajar dan berfikir bahwa pembelajaran itu menyenangkan apalagi jika guru yang mengajar menggunakan berbagai media sosial yang sudah biasa digunakan oleh siswa untuk berkomunikasi.

\section{UCAPAN TERIMA KASIH}

Penulis mengucapkan terimakasih kepada rekan-reakan dosen di lingkungan Program Studi Pendidikan Guru Madrasah Ibtidaiyah Pascasarjana, IAIN Purwokerto atas dukungannya dalam menyelesaikan penelitian ini. Penulis juga berterimakasih kepada pihak- pihak yang telah mendukung penelitian ini.

\section{DAFTAR PUSTAKA}

AHM Production. Mengenal Media Sosial, 2021.

https://www.youtube.com/watch?v=r hg0xtrDRWc.

. Peran Dan Fungsi Sosial Media, 2020.

https://www.youtube.com/watch?v=a Mg71DGRNAE.

Bung Fahdisjro. Globalisasi; Pengertian, Faktor Penyebab \& Dampaknya | Motion Graphics, 2018. https://www.youtube.com/watch?v= FXLeEPWpRCI.

Fitriani, Yuni. "Analisis Pemanfaatan Berbagai Media Sosial sebagai Sarana Penyebaran Informasi bagi Masyarakat." Paradigma - Jurnal Komputer dan Informatika 19, no. 2 (October 11, 2017): 148-52. https://doi.org/10.31294/p.v19i2.212 $\underline{0}$. 
Ningsih, Tutuk. "Pendidikan Multikultural Dalam Membentuk Karakter Bangsa Melalui Pembelajaran IPS Di Sekolah Confucius Terpadu SD Mulia Bakti Purwokerto Kabupaten Banyumas." INSANIA: Jurnal Pemikiran Alternatif Kependidikan 22, no. 2 (September 11, 2017): 366-77. https://doi.org/10.24090/insania.v22i 2.1225 .

Nurhayati, Anastasia Siti. "PERAN MEDIA JEJARING SOSIAL DALAM PEMBELAJARAN ABAD 2," 2016, 11.

Nurrizka, Annisa Fitrah. "PERAN MEDIA SOSIAL DI ERA GLOBALISASI PADA REMAJA DI SURAKARTA (SUATU KAJIAN TEORITIS DAN PRAKTIS TERHADAP REMAJA DALAM PERSPEKTIF PERUBAHAN SOSIAL)." Jurnal Analisa Sosiologi 5, no. 1 (February 10 , 2018). https://doi.org/10.20961/jas.v5i1.181 $\underline{98}$.

Ricky, and Erry Hendriawan. "Implementasi Model Pendidikan Masyarakat pada Era Globalisasi." MIMBAR PENDIDIKAN 5, no. 2 (October 11, 2020): 161-76. https://doi.org/10.2121/mp.v5i2.1356

Suriyanti, Yulia, and Munawar Thoharudin. "Pemanfaatan Media Pembelajaran IPS Untuk Meningkatkan Keterampilan Guru IPS Terpadu." JPPM (Jurnal Pengabdian Dan Pemberdayaan Masyarakat) 3, no. 1 (March 19, 2019): 117-21. https://doi.org/10.30595/jppm.v3i1.3 $\underline{507 .}$.

Unacademy - Indonesia. Definisi Dan Teori Globalisasi (Sosiologi - SBMTPN, UN, $\quad 2017$. https://www.youtube.com/watch?v=f pjvLNw9-6Q.

Wolf, Martin. Globalisasi: jalan menuju kesejahteraan. Yayasan Obor Indonesia, 2007. 